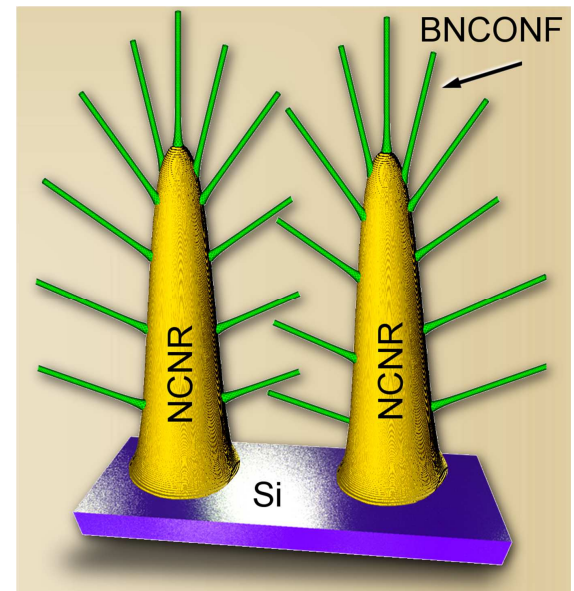




\section{Pillar BNCO nanoflake/nanorod hybrid networks synthesized by plasma-enhanced hot filament CVD: structure and photoluminescence}

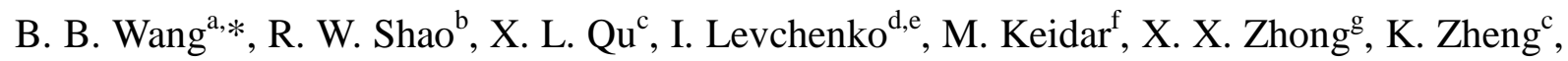
S. $\mathrm{Xu}^{\mathrm{d}}$, K. Ostrikov ${ }^{\mathrm{e}, \mathrm{h}, \mathrm{i}}$

${ }^{a}$ College of Chemistry and Chemical Engineering, Chongqing University of Technology, 69 Hongguang $R d$, Lijiatuo, Banan District, Chongqing 400054, P. R. China.

${ }^{b}$ Electron Microscopy Laboratory, School of Physics, Peking University, Beijing 100871, China.

'Institute of Microstructure and Properties of Advanced Materials, Beijing University of Technology, Beijing 100124, P. R. China.

${ }^{d}$ Plasma Sources and Applications Centre, National Institute of Education, Nanyang Technological University, 1 Nanyang Walks, 637616, Singapore

${ }^{e}$ School of Chemistry, Physics and Mechanical Engineering, Queensland University of Technology, Brisbane QLD 4000, Australia.

${ }^{f}$ Mechanical and Aerospace Engineering, The George Washington University, Washington DC 20052, USA.

${ }^{g}$ Department of Physics and Astronomy, Shanghai Jiao Tong University, Shanghai 200240, P. R. China

${ }^{h}$ CSIRO-QUT Joint Sustainable Materials and Devices Laboratory, Commonwealth Scientific and Industrial Research Organization, P.O. Box 218, Lindfield NSW 2070, Australia.

'Plasma Nanoscience, School of Physics, The University of Sydney, Sydney NSW 2006, Australia.

\footnotetext{
* Corresponding author at: College of Chemistry and Chemical Engineering, Chongqing University of Technology, 69 Hongguang Rd, Lijiatuo, Banan District, Chongqing 400054, P. R. China. E-mail address: bibenw@cqut.edu.cn (B. B. Wang).
} 


\section{Abstract}

Theoretical studies of the complex, doped BN/carbon pillar hybrid networks have revealed their great potential for energy and power conversion, nanoelectronics, optoelectronics and electric propulsion devices. Demonstration of the technique to synthesise such networks and control the structure is critical for their applications. Here we report on the successful fabrication of complex, hybrid pillar networks consisting of carbon- and oxygen-doped BN nanoflakes and nitrogenated carbon nanorods. The complex, hybrid, structure-controlled pillar networks were grown directly on the carbon nanorods in $\mathrm{N}_{2}-\mathrm{H}_{2}$ plasma using $\mathrm{B}_{4} \mathrm{C}$ as the boron and carbon sources. The characterization by scanning and transmission electron microscopy, micro-Raman, Fourier transform infrared and X-ray photoelectron spectroscopies has confirmed that the carbon- and oxygen-doped $\mathrm{BN}$ crystalline nanoflakes indeed grow on the amorphous nitrogenated carbon nanorods and form the pillar hybrid networks. The photoluminescence measurements have revealed that the pillar hybrid networks generate ultraviolet, blue, green, and red photoluminescence bands. In particular, the photoluminescence properties of the pillar hybrid networks can be effectively tuned by changing the network structure. These outcomes can contribute to the synthesis of novel nanostructures and the development of next generation optoelectronic nanodevices and power devices. 


\section{Introduction}

Recently, hybrid nanostructures on the base of graphene flakes have attracted increased interest due to the intrinsic synergistic effects and extensive applications of these structures in various advanced nanodevices including highly sensitive sensors and efficient solar cells [1-3]. To date, a large number of reports was published on the hybrid graphene-containing nanostructures such as graphene/carbon nanotube composites, graphene/transition metal dichalcogenide and graphene/zinc oxide structures, graphene/Cu-Ni alloys and graphene/BN hybrid nanomaterials. Numerous publications on their applications in the areas of microelectronic devices, optoelectronic devices, electrocatalysis, Li cells and solar cells were also issued [1, 3-9].

Hexagonal boron nitride (h-BN) is a layered structural insulator material with a wide bandgap $(\sim 5.5 \mathrm{eV})[8]$, which has the same atomic structure as graphene except for a small $(1.8 \%)$ lattice mismatch. As a result, it possesses a number of similar properties with graphene [10]. Furthermore, h-BN can be doped by other elements such as carbon and oxygen to become a semiconductor [11,12]; hence, the electronic structure and properties of h-BN can be tuned so that it can be used in microelectronic and optoelectronic devices [11-13].

Since h-BN has structure and properties similar to those of graphene, great efforts have been recently paid to study BN-based nanomaterials and their hybrid structures [14]. The obtained results indicate that the $\mathrm{BN} /$ graphene hybrid structures exhibit some novel physical properties such as fractional quantum Hall effect, superlattice Dirac points and high carrier mobility [15-17]. Importantly, recent theoretical studies indicate that the hybrid networks of the doped BN pillars incorporating the graphene flakes possess high capacity of hydrogen storage due to the large surface area of pillar structures and polarization of hydrogen caused by the charges of doped atoms [18]. Apparently, these features ensure important applications 
of the material in the energy and power units of transport vehicles. Furthermore, the hybrid pillar networks could also be efficiently used in the nanoelectronics and optoelectronics due to their ultrahigh surface area and lightweight structure [19], and hence, investigation of the doped $\mathrm{BN} /$ carbon pillar hybrid structures is important to develop novel nanoelectronic, optoelectronic, and hydrogen-powered devices. Indeed, the doped BN nanoflake/carbon pillar networks made of doped $\mathrm{BN}$ nanoflakes incorporating the pillar carbon nanomaterials feature the surface area larger than that of a simple hybrid of doped $\mathrm{BN}$ pillars and graphene nanoflakes. Hence, the doped $\mathrm{BN} /$ carbon pillar hybrid networks can further improve the properties of doped BN nanoflakes. This work aims to synthesize the doped hybrid $\mathrm{BN} /$ carbon pillar networks and demonstrate their key properties.

Synthesis of the doped BN/hybrid structures involves the two key steps, namely doping of h-BN and connection of the doped $\mathrm{BN}$ nanoflakes to carbon pillars. With respect to the first step, appropriate doping elements must be found to replace the boron or nitrogen atoms in the h-BN structure [12]. Previously conducted studies indicate that the carbon atoms of graphite structure are easily substituted by boron or nitrogen, and the oxygen atoms can easily enter hexagonal $s p^{2}$-type lattice of graphene and h-BN $[11,20]$; thus, carbon and oxygen are the ideal doping elements in h-BN. As the result of these findings, carbon/oxygen co-doped BN nanoflakes (i.e., BNCONFs) have been successfully synthesized using the plasma-enhanced hot filament chemical vapour deposition (PEHFCVD) [21, 22]. On the other hand, the carbon pillars such as carbon nanorods can also be prepared by PEHFCVD [23]. How to connect BNCONFs to the carbon nanorods? It is known that heteroatoms and molecules are easily binding to atoms with dangling bonds. If some carbon atoms on the surfaces of carbon pillars are removed, the dangling bonds will appear on the pillar surfaces. In this work, the dangling bonds were created on the nitrogenated carbon nanorods (NCNRs) 
through the bombardment by the plasma-produced ions, and then the carbon/oxygen co-doped BN nanoflakes were directly grown on the NCNRs to form the pillar BNCONF/NCNR hybrid structures. Due to the change of electric field pattern around NCNRs, the BN nanoflakes growing on the NCNRs form the diversified pillar BNCONF/NCNRs hybrid networks.

High quantum efficiency of the BNCO nanomaterials makes them promising for many devices requiring tenability of the photoluminescent properties [13]. In the light of this, the photoluminescent (PL) properties of pillar BNCONF/NCNRs hybrid networks were also studied in this work, and it is found that they can be tuned by the pillar BNCONF/NCNRs hybrid networks.

\section{Experimental}

\subsection{Preparation of Samples}

First, silicon wafers were ultrasonically cleaned in the solutions of methyl benzene, acetone and ethyl alcohol for $15 \mathrm{~min}$, and then boiled at $75{ }^{\circ} \mathrm{C}$ for $15 \mathrm{~min}$ in the solution composed of $\mathrm{NH}_{3} \cdot \mathrm{H}_{2} \mathrm{O}, \mathrm{H}_{2} \mathrm{O}_{2}$ and deionized water. Next, a gold film with a thickness of $\sim 15 \mathrm{~nm}$ was deposited on the cleaned silicon wafers.

The syntheses of the nitrogenated carbon nanorods, carbon- and oxygen-doped BN nanoflakes and pillar BNCONF/NCNR hybrid networks were carried out in the PEHFCVD system described elsewhere [22]. In the CVD chamber, three coiled tungsten filaments heated up by $\mathrm{AC}$ power supply were used to heat the substrate, decompose reactive gases and evaporate the source materials. A DC power supply whose positive and negative electrodes were connected to the filaments and substrate was used to ignite and sustain the plasma for the growth of the above nanomaterials. The substrate was placed on molybdenum located about $10 \mathrm{~mm}$ below the filaments. 
Table 1. Flow rates of gases, growth temperature $(T)$, bias current $\left(I_{b}\right)$ and growth time $(t)$

\begin{tabular}{c|c|c|c|c|c|c|c|c}
\hline Sample & Substrate & $\mathrm{T}\left({ }^{\circ} \mathrm{C}\right)$ & $\mathrm{CH}_{4}(\mathrm{sccm})$ & $\mathrm{N}_{2}(\mathrm{sccm})$ & $\mathrm{H}_{2}(\mathrm{sccm})$ & $I_{\mathrm{b}}(\mathrm{mA})$ & $t(\mathrm{~min})$ & $\mathrm{B}_{4} \mathrm{C}$ \\
\hline $\mathrm{A}$ & $\mathrm{Au} / \mathrm{Si}$ & $\sim 890$ & - & 50 & 50 & 160 & 15 & With \\
$\mathrm{B}$ & $\mathrm{Au} / \mathrm{Si}$ & $\sim 880$ & 20 & 40 & 40 & 160 & 15 & - \\
$\mathrm{C}$ & $\mathrm{Au} / \mathrm{Si}$ & $\sim 880$ & 20 & 40 & 40 & 160 & 20 & - \\
$\mathrm{D}$ & Sample A & $\sim 890$ & - & 50 & 50 & 160 & 15 & With \\
$\mathrm{E}$ & Sample B & $\sim 890$ & - & 50 & 50 & 160 & 20 & With \\
\hline
\end{tabular}

All the above described nanomaterials were synthesized by the same procedures except for the different synthesis conditions, which were as follows. When the CVD chamber was evacuated lower than $2 \mathrm{~Pa}$, reactive gases were fed to the chamber, the pressure in the chamber was maintained at about $2 \times 10^{3} \mathrm{~Pa}$ through vacuum valve, and the filaments were heated to about $1800{ }^{\circ} \mathrm{C}$ by AC power supply. After that, the substrate was quickly heated up by the filaments due to a short distance between the filaments and substrate. Once substrate temperature reached the growth temperature, a DC power supply was turned on to ignite the plasma, and then the bias current was supplied to start the growth of the nanomaterials. In this work, five samples A-E were prepared by the growth conditions listed in Table 1.

Specifically, sample $A$ is the BNCONFs grown in $\mathrm{N}_{2}-\mathrm{H}_{2}$ plasma for 15 min using $\mathrm{B}_{4} \mathrm{C}$ as the precursors of boron and carbon; the $\mathrm{B}_{4} \mathrm{C}$ sheets pressed by $\mathrm{B}_{4} \mathrm{C}$ powder were placed near the silicon substrate [22]. Samples B and C are the NCNRs grown in the $\mathrm{CH}_{4}-\mathrm{N}_{2}-\mathrm{H}_{2}$ plasma for 15 and $20 \mathrm{~min}$, respectively. Samples D and E are the pillar BNCONF/NCNR hybrid networks grown on samples $\mathrm{B}$ and $\mathrm{C}$ in the $\mathrm{N}_{2}-\mathrm{H}_{2}$ plasma for 15 min using $\mathrm{B}_{4} \mathrm{C}$ as the precursors of boron and carbon, respectively. 


\subsection{Characterization}

Structure and composition of the samples were characterized by a series of characterization instruments including S-4800 field emission scanning electron microscope (FESEM), JEOL 2010F high-resolution transmission electron microscopy (TEM), HR 800 micro-Raman spectroscope using the $532 \mathrm{~nm}$ line of semiconductor laser as the excitation source, BIORAD60V Fourier transform infrared spectroscope (FTIR) and ESCALAB 250 X-ray photoelectron spectroscope (XPS) using $\mathrm{Al} \mathrm{K \alpha}$ X-ray source. The PL properties of the samples were studied out at room temperature in a Horiba Scientific Labram HR evolution Raman spectrometer under the excitation of $325 \mathrm{~nm}$ line of $\mathrm{He}-\mathrm{Cd}$ laser, where the power was $1.3 \mathrm{~mW}$ and the diameter of the light spot was about $1 \mu \mathrm{m}$.

\section{Results and discussion}

\subsection{Structure and composition of samples}

Figure 1 is the FESEM images of samples A-E. In Fig.1 one can see that samples A-C are composed of the aligned nanoflakes and nanorods, whereas samples D and E are the pillar network structures composed of nanoflakes and nanorods, respectively. Comparing Fig. 1(d) and (e) with Fig. 1(a) one can also find that the area of diversified nanoflakes grown on the nanorods is smaller than that of nanoflakes grown on the silicon substrate covered with gold film. However, the connection of top edges of some aligned nanoflakes shown in Fig. 1(a) implies that the surface area of the aligned nanoflakes is reduced. Besides, Fig. 1(c) indicates that some gold nanoparticles on the tops of nanorods were removed from the nanorods due to the ion bombardment for a long time. 


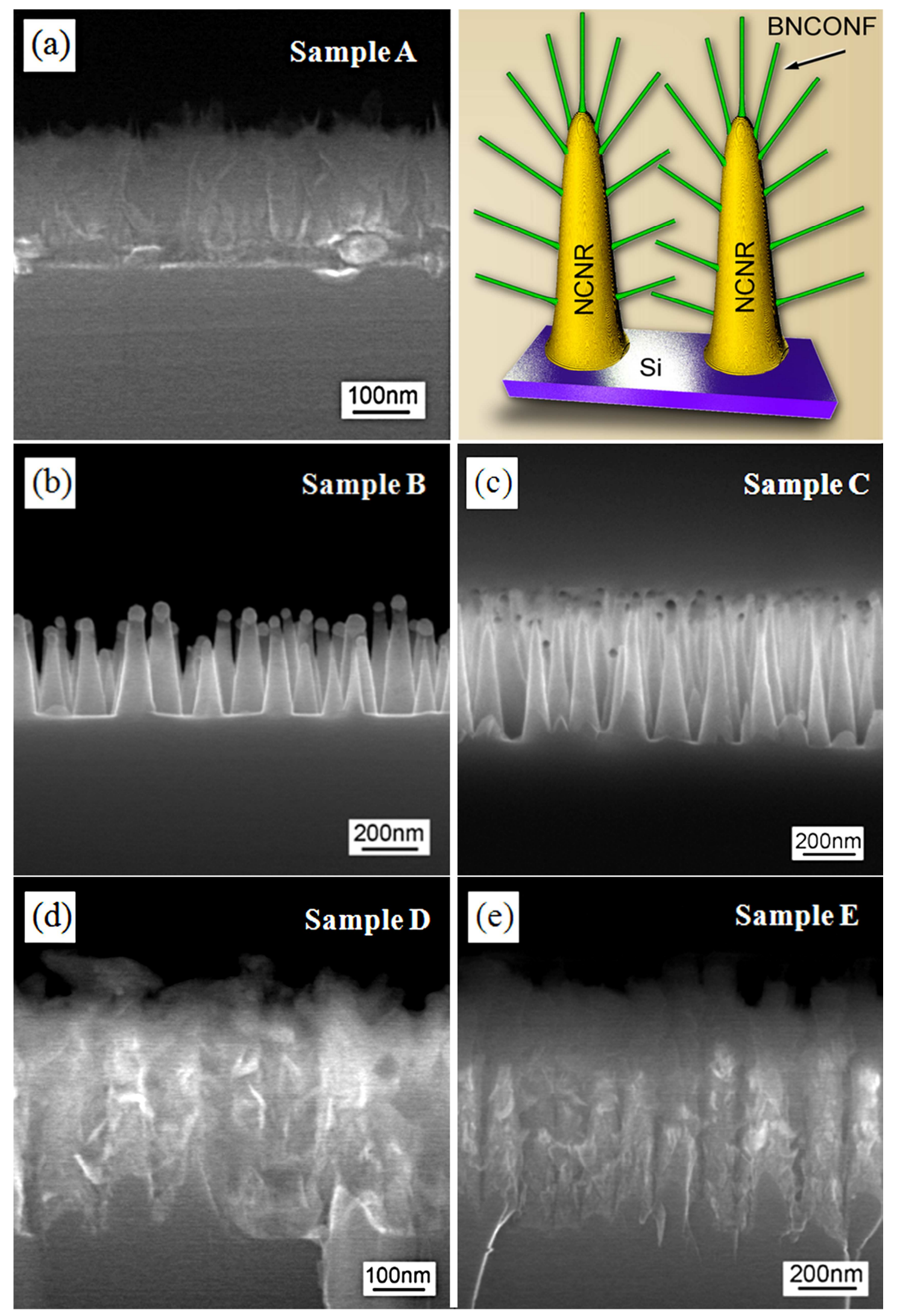

Figure 1. FESEM images of samples. (a) Aligned nanoflakes; (b) and (c) pillar nanorods grown for 15 and $20 \mathrm{~min}$; (d) and (e) show that the nanoflakes grow on the pillar nanorods. The area of diversified nanoflakes grown on the nanorods is smaller than that of nanoflakes grown on the silicon substrate covered with gold film. Colour inset illustrates the structure of the synthesised complex network. 

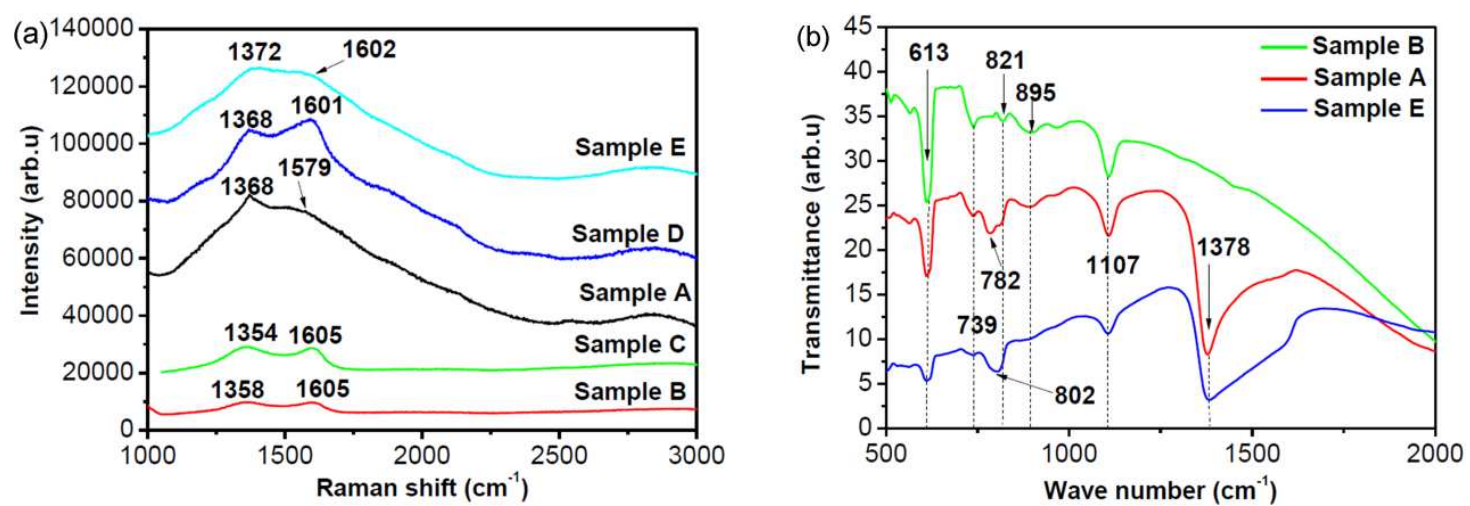

Figure 2. Raman spectra of samples (a) and FTIR spectra of samples A, B and E (b). (a) The two Raman peaks in the spectra of samples B and C indicate that these samples are amorphous carbon structure. The Raman peaks at about $1368-1372 \mathrm{~cm}^{-1}$ result from the vibration of B-N bonds in h-BN, and the peaks at about $1579-$ $1602 \mathrm{~cm}^{-1}$ are related to $\mathrm{C}=\mathrm{C}$ bonds. (b) The peaks at about 613 and $1107 \mathrm{~cm}^{-1}$ are related to $\mathrm{O}-\mathrm{C}-\mathrm{O}$ bonds and C-O-C bonds, the peaks at about 739 and $895 \mathrm{~cm}^{-1}$ are associated to $\mathrm{C}-\mathrm{N}$ and N-H bonds, the peaks at about 782 and $1378 \mathrm{~cm}^{-1}$ are attributed to B-N-B and B-N bonds, and the peaks at 802 and $821 \mathrm{~cm}^{-1}$ link to the C-H bonds, respectively.

Figure 2(a) is the Raman spectra of all five samples. As shown in Fig. 2, the Raman spectra of samples B and C feature two Raman peaks at about $1354-1358$ and $1605 \mathrm{~cm}^{-1}$, which are the peaks of amorphous carbon [23]. In the Raman spectra of samples A, D and E, the Raman peaks at about 1368 and $1372 \mathrm{~cm}^{-1}$ are related to the $\mathrm{B}-\mathrm{N}$ bonds in h-BN [24,25], whereas the Raman peaks at about $1579-1602 \mathrm{~cm}^{-1}$ are associated to the $\mathrm{C}=\mathrm{C}$ bonds [26]. These Raman peaks suggest that sample A is a h-BN structure mixed with impurities, samples $\mathrm{B}$ and $\mathrm{C}$ are amorphous carbon, and samples $\mathrm{D}$ and $\mathrm{E}$ contain $\mathrm{h}-\mathrm{BN}$ phases, respectively.

To further examine and confirm the composition, samples A, B and E were studied by FTIR and XPS and the results are shown in Fig. 2(b), 3 and 4. Fig. 2(b) shows the FTIR spectra of samples A, B and E. As it can be seen in this figure, the spectra show peaks at about 613, 739, 895, and $1107 \mathrm{~cm}^{-1}$, respectively. Specifically, the peaks about 613 and $1107 \mathrm{~cm}^{-1}$ are related to O-C-O and C-O-C or C-B bonds [27-29], while the peaks at about 739 and 895 $\mathrm{cm}^{-1}$ are associated with $\mathrm{C}-\mathrm{N}$ and $\mathrm{N}-\mathrm{H}$ bonds, respectively [30,31]. 


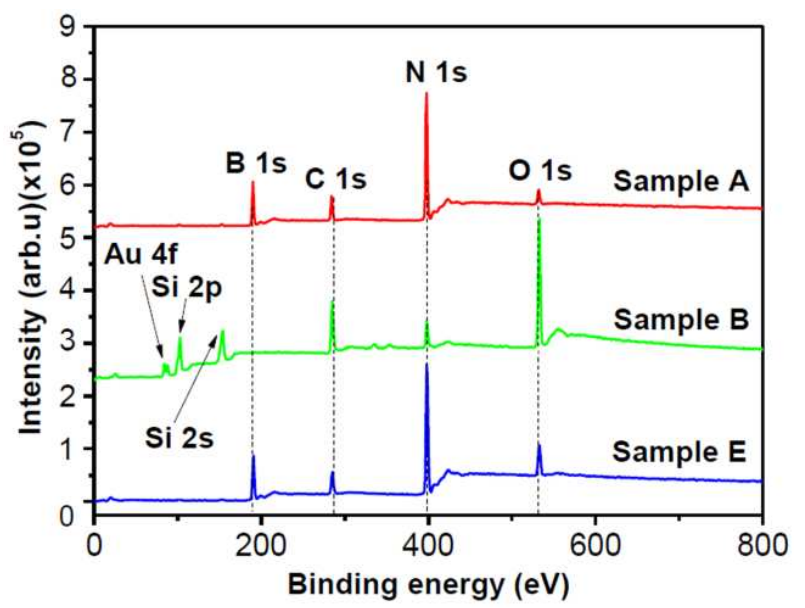

Figure 3. XPS spectra of samples A, B and E. The peaks at about 190.6, 284.8, 398.2-398.5 and 532.7 $\mathrm{eV}$ are assigned to $\mathrm{B} 1 \mathrm{~s}, \mathrm{C} 1 \mathrm{~s}, \mathrm{~N}$ 1s and $\mathrm{O} 1 \mathrm{~s}$, and the peaks at about 84.2, 102.8 and $153.9 \mathrm{eV}$ are related to $A u 4 f$, Si $2 p$ and Si 2 s, respectively.

Besides these four peaks, Fig. 2(b) also shows other four peaks located at about 782, 802, 821 and $1378 \mathrm{~cm}^{-1}$, respectively. The two peaks at about 782 and $1378 \mathrm{~cm}^{-1}$ are attributed to the vibrations of B-N-B and B-N bonds [32], and the peak at $821 \mathrm{~cm}^{-1}$ links to the $\mathrm{C}-\mathrm{H}$ bonds [33]. The origin of peak at about $802 \mathrm{~cm}^{-1}$ is not clear, it may relate to the $\mathrm{C}-\mathrm{H}$ bonds because the Raman peak related to C-H bonds is found at about $809 \mathrm{~cm}^{-1}$ [34].

Figure 3 is the XPS spectra of samples A, B and E. As shown in this figure, the XPS spectra of A and E show the B 1s, C 1s, N 1s and O 1s peaks at about 190.6, 284.8,398.5 and $532.7 \mathrm{eV}$, while the spectrum of sample B shows the $\mathrm{C} 1 \mathrm{~s}, \mathrm{~N} 1 \mathrm{~s}$ and $\mathrm{O} 1 \mathrm{~s}$ peaks at about 284.8, 398.2 and $532.6 \mathrm{eV}$, respectively. In the spectrum of sample $\mathrm{B}$, the peak at about $84.2 \mathrm{eV}$ is attributed to $\mathrm{Au}$ 4f and the peaks at about 102.8 and $153.9 \mathrm{eV}$ are related to Si $2 \mathrm{p}$ and $\mathrm{Si} 2 \mathrm{~s}$, respectively [35].

Using the XPS results, we have obtained the concentrations of elements, and they are listed in Table 2. The ratio of $\mathrm{B}$ to $\mathrm{N}$ atoms is about 1.1 and 1.3 for samples $\mathrm{A}$ and $\mathrm{E}$, respectively. These data are slightly larger than the stoichiometric ratio of h-BN, which may result from the incorporation of $\mathrm{B}_{2} \mathrm{O}_{3}$ molecules and carbon atoms. 


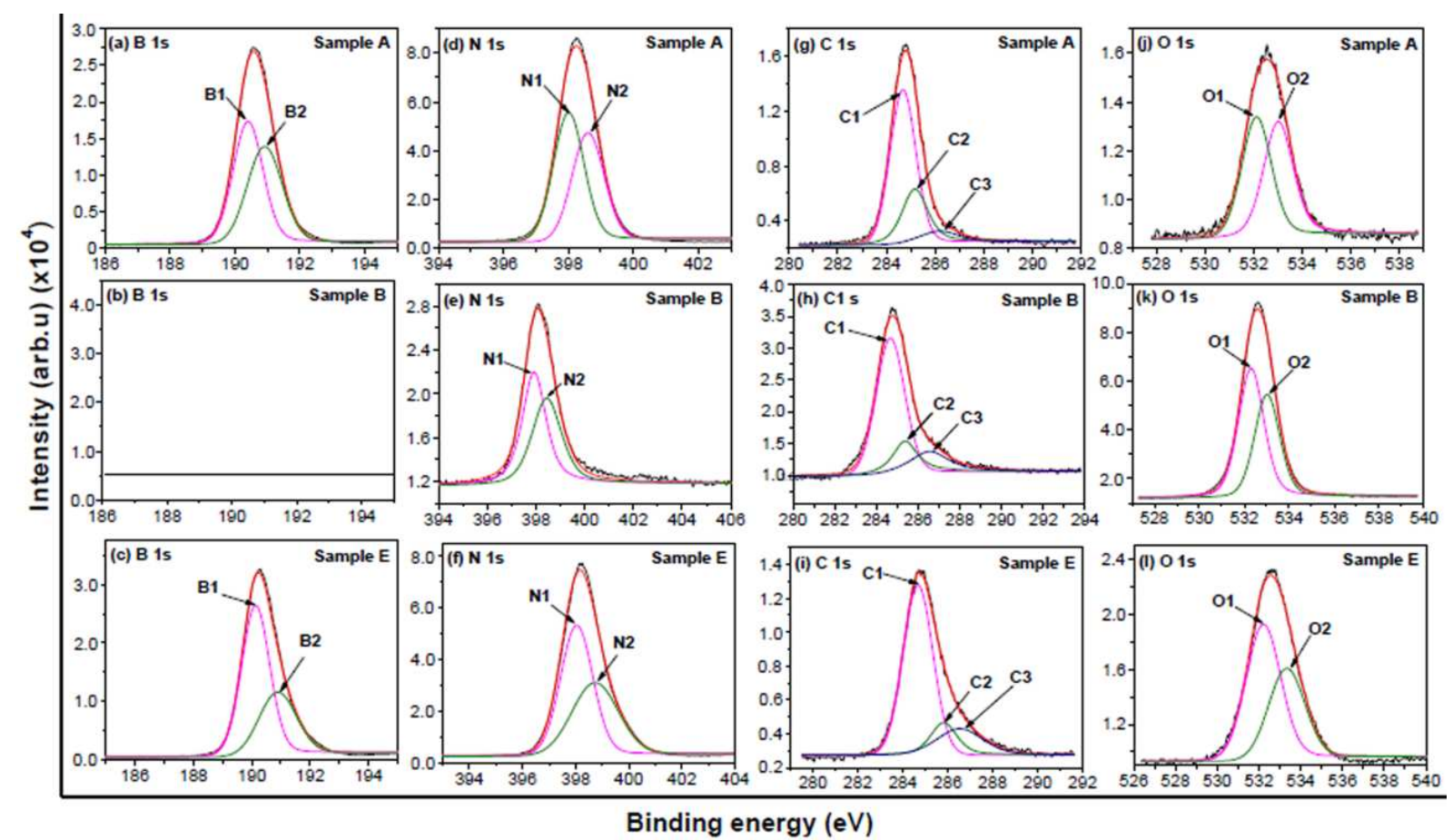

Figure 4. $B$ 1s, N1s, $C$ 1s and $O$ 1s XPS peaks of samples $A, B$ and $E$, respectively. The $B 1$ and $B 2$ peaks are attributed to $\mathrm{B}-\mathrm{N}$ and $\mathrm{N}-\mathrm{B}-\mathrm{O}$ bonds, the $\mathrm{C} 1, \mathrm{C} 2$ and $\mathrm{C} 3$ are assigned to the $s p^{2} \mathrm{C}-\mathrm{C}, s p^{3} \mathrm{C}-\mathrm{C}$ and $\mathrm{C}-\mathrm{N}$ bonds, and the $\mathrm{O} 1$ and $\mathrm{O} 2$ peaks are relevant to the $\mathrm{C}-\mathrm{O}-\mathrm{C},-\mathrm{OH}$ and $\mathrm{B}-\mathrm{O}$ bonds, respectively. The $\mathrm{N} 1$ and $\mathrm{N} 2$ peaks of samples $\mathrm{A}$ and $\mathrm{E}$ are attributed to the $\mathrm{B}-\mathrm{N}$ and N-B-O bonds, while the $\mathrm{N} 1$ and $\mathrm{N} 2$ peaks of sample $\mathrm{B}$ are related to Au-N or Si-N and C-N bonds, respectively.

Table 2 Concentrations of B, N, C and O elements in the samples A, B and E.

\begin{tabular}{ccccc}
\hline Sample & B(at\%) & N(at\%) & C(at\%) & O(at\%) \\
\hline A & 44.09 & 39.24 & 13.35 & 3.32 \\
B & - & 9.2 & 31.21 & 28.14 \\
E & 45.83 & 36.12 & 11.33 & 5.98 \\
\hline
\end{tabular}

Figure 4 shows the amplified B 1s, N1s, C 1s and O 1s XPS peaks of samples A, B and E, respectively. To obtain the binding states of the elements, these XPS peaks were fitted using the standard XPS fitting software. The positions of fitted peaks are given in Table 3. In Fig. 4, the $\mathrm{B} 1$ and $\mathrm{B} 2$ peaks are attributed to $\mathrm{B}-\mathrm{N}$ and $\mathrm{N}-\mathrm{B}-\mathrm{O}$ bonds; the $\mathrm{C} 1, \mathrm{C} 2$ and $\mathrm{C} 3$ are related to the $s p^{2} \mathrm{C}-\mathrm{C}, s p^{3} \mathrm{C}-\mathrm{C}$ and $\mathrm{C}-\mathrm{N}$ bonds, respectively [35,36]. The $\mathrm{N} 1$ and $\mathrm{N} 2$ peaks of sample A and $\mathrm{E}$ are associated with the $\mathrm{B}-\mathrm{N}$ and $\mathrm{C}-\mathrm{N}$ bonds [35], while the $\mathrm{N} 1$ and $\mathrm{N} 2$ of sample $\mathrm{B}$ are attributed to the $\mathrm{Au}-\mathrm{N}$ or $\mathrm{Si}-\mathrm{N}$ and $\mathrm{C}-\mathrm{N}$ bonds, respectively [37-39]. The $\mathrm{O} 1$ and $\mathrm{O} 2$ peaks are relevant to the $\mathrm{C}-\mathrm{O}-\mathrm{C},-\mathrm{OH}$ and $\mathrm{BO}$ bonds, respectively $[35,36]$. 
Table 3. Positions of fitted peaks in Figure 5.

\begin{tabular}{cccccccccc}
\hline Sample & $\mathrm{B} 1(\mathrm{eV})$ & $\mathrm{B} 2(\mathrm{eV})$ & $\mathrm{N} 1(\mathrm{eV})$ & $\mathrm{N} 2(\mathrm{eV})$ & $\mathrm{C} 1(\mathrm{eV})$ & $\mathrm{C} 2(\mathrm{eV})$ & $\mathrm{C} 3(\mathrm{eV})$ & $\mathrm{O} 1(\mathrm{eV})$ & $\mathrm{O} 2(\mathrm{eV})$ \\
\hline A & 190.4 & 190.9 & 398.0 & 398.6 & 248.7 & 285.2 & 286.3 & 532.3 & 533.2 \\
B & - & - & 397.9 & 398.5 & 248.7 & 285.4 & 286.6 & 532.3 & 533.0 \\
E & 190.1 & 190.9 & 398.0 & 398.8 & 284.7 & 285.8 & 286.5 & 532.2 & 533.3 \\
\hline
\end{tabular}
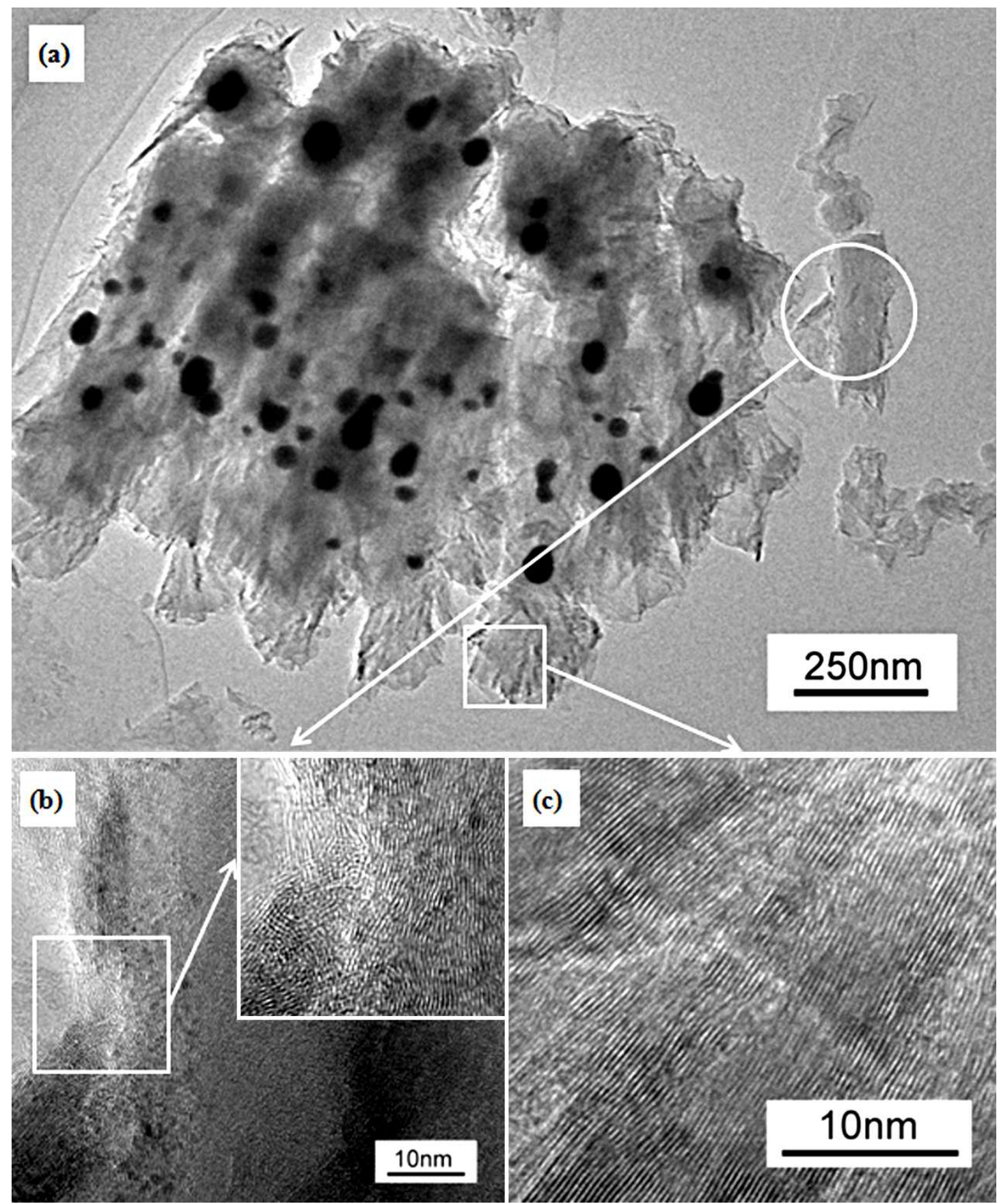

Figure 5. HRTEM images of sample E. (a) Nanoflakes growing on the nanorods. (b) The amorphous nanorod is covered with the crystalline phase. (c) The nanoflake is a crystalline structure mixed with the amorphous phase. 
In the previous works, nanoflakes and nanorods were studied by TEM which has indicated their crystalline and amorphous structures, respectively [21, 23, 40]. Here sample E was studied by high-resolution (HR) TEM and the results are shown in Figure 5. From this figure one can see that the nanoflakes grow directly on the nanorods. The HRTEM image (b) indicates that the nanorod is an amorphous structure covered with the crystalline phases, which is confirmed by the inset in Fig. 5(b). The HRTEM image (c) shows that the nanoflakes are crystalline structures mixed with some amorphous phase.

The above characterization results indicate that sample $\mathrm{A}$ is composed of h-BN phase mixed with carbon and oxygen (i.e., it is BNCONFs); samples $\mathrm{B}$ and $\mathrm{C}$ are made of nitrogenated amorphous carbon nanorods (i.e., NCNRs), and samples D and E are the NCNRs covered with BNCONFs.

\subsection{Formation of pillar BNCONF/CNR hybrid networks}

Some details of the NCNRs and BNCONFs formation mechanism were studied in the previous works $[21-23,40]$. The formation of BNCONFs results from the h-BN nucleation followed by self-assembly of BN molecules on gold nanoparticles, and incorporation of the carbon atoms and $\mathrm{B}_{2} \mathrm{O}_{3}$ molecules into h-BN structure where the carbon atoms, $\mathrm{B}_{2} \mathrm{O}_{3}$ and $\mathrm{BN}$ molecules are formed via a series of reactions listed below.

Due to the intense heating of the substrate, $\mathrm{B}_{4} \mathrm{C}$ evaporated to boron and carbon atoms,

$$
\mathrm{B}_{4} \mathrm{C} \rightarrow 4 \mathrm{~B}+\mathrm{C} .
$$

Furthermore, a number of $\mathrm{N}^{+}, \mathrm{H}^{+}$and $\mathrm{NH}_{3}{ }^{+}$ions were formed after the $\mathrm{N}_{2}-\mathrm{H}_{2}$ plasma was ignited [41]. $\mathrm{N}^{+}$and $\mathrm{H}^{+}$bombarded the $\mathrm{B}_{4} \mathrm{C}$ sheets near $\mathrm{Si}$ substrate and sputter them, thus the carbon and boron atoms were formed. The boron atoms react with the residual $\mathrm{O}_{2}$ in the CVD 
chamber to form $\mathrm{B}_{2} \mathrm{O}_{3}$ molecules,

$$
\mathrm{B}+\mathrm{O}_{2} \rightarrow \mathrm{B}_{2} \mathrm{O}_{3}
$$

The $\mathrm{B}_{2} \mathrm{O}_{3}$ molecules react with the $\mathrm{NH}_{3}{ }^{+}$ions to form $\mathrm{BN}$ molecules,

$$
\mathrm{B}_{2} \mathrm{O}_{3}+2 \mathrm{NH}_{3}^{+}+\mathrm{e} \rightarrow 2 \mathrm{BN}+3 \mathrm{H}_{2} \mathrm{O}
$$

and the reaction of boron atoms with $\mathrm{N}^{+}$ions also leads to the formation of $\mathrm{BN}$ molecules:

$$
\mathrm{B}+\mathrm{N}^{+}+\mathrm{e} \rightarrow \mathrm{BN}
$$

When substrate is being heated, the gold film fractures and forms nanoparticles due to the mechanical stress $[42,43]$. The BN molecules deposit on the surfaces of gold nanoparticles, then nucleate and form the h-BN nanosheets. At the same time, some carbon atoms and $\mathrm{B}_{2} \mathrm{O}_{3}$ molecules deposit onto the h-BN nanosheets and incorporate into the h-BN nanosheets. Due to the incorporation of these (i.e., carbon and oxygen) atoms, a stress was produced in the h-BN nanosheets. As a result, the growth of h-BN nanosheets transformed from the growth along the surfaces of gold nanoparticles to the up growth to form the vertically aligned BNCONFs [44]. The formation of NCNRs is similar to the growth of carbon nanotubes: the $\mathrm{CH}_{3}{ }^{+}$and $\mathrm{N}^{+}$ions produced by $\mathrm{CH}_{4}-\mathrm{N}_{2}-\mathrm{H}_{2}$ plasma deposit on the gold nanoparticles to form carbon and nitrogen atoms, which dissolve into the gold nanoparticles; then, dissolved carbon and nitrogen atoms diffuse toward the bottom of gold nanoparticles and precipitate from the gold nanoparticles to form the nanorods. More details on the formation of BNCONFs and NCNRs can be found in Refs. [21-23, 40]. Here we study the details of the formation of pillar BNCONF/NCNR hybrid networks.

Due to the bombardment of $\mathrm{N}^{+}$and $\mathrm{H}^{+}$ions from the plasma, the NCNRs formed on the substrate surface are sputtered. As a consequence, some dangling bonds are formed on the surfaces of NCNRs due to the removal of some atoms off the NCNRs surface. Simultaneously, $\mathrm{B}_{4} \mathrm{C}$ evaporates dye to the bombardment, so the $\mathrm{BN}$ molecules are formed via the reactions 
(1)-(4). Then, the BN molecules deposit onto the surfaces of NCNRs and easily bind to the dangling bonds, which serve as the nucleation centres of the h-BN nanosheets. Due to the continuous deposition of BN molecules, they move toward the BN nuclei and bond to them, finally forming the h-BN nanosheets. Furthermore, some of carbon and boron atoms, $\mathrm{B}_{2} \mathrm{O}_{3}$ molecules, $\mathrm{N}^{+}$and $\mathrm{NH}_{3}{ }^{+}$ions deposit on the h-BN nanosheets. According to reactions (3) and (4), the interaction between the $\mathrm{B}_{2} \mathrm{O}_{3}$ molecules and $\mathrm{NH}_{3}{ }^{+}$ions and between the boron atoms and $\mathrm{N}^{+}$ions form the $\mathrm{BN}$ molecules, which contribute to the normal growth of the h-BN nanosheets. At the same time, some of the BN molecules diffuse toward the edges of the $\mathrm{h}-\mathrm{BN}$ nanosheets and bond to the edges of the h-BN nanosheets, thus promoting the enlargement of the h-BN nanosheets. Some $\mathrm{B}_{2} \mathrm{O}_{3}$ molecules do not react with the $\mathrm{NH}_{3}{ }^{+}$ions, so a certain amount of $\mathrm{B}_{2} \mathrm{O}_{3}$ retains in the h-BN nanosheets. Besides, the carbon atoms deposited onto the h-BN nanosheets also retain in the h-BN nanosheets. Hence, the carbon and oxygen atoms as the heterogeneous species lead to the production of stress at the h-BN nanosheets [44]. When the stress is strong enough, the growth of h-BN nanosheets is transformed from the growth along the surfaces of NCNRs to the up growth to form the pillar BNCONF/NCNR hybrid structures, as evidenced by Fig. 5(b).

Figures 1(b) and (c) also show that the NCNRs are the cone-like structures. As a result, the electric field near the NCNRs becomes distorted, as illustrated in Figure 6 [45]. Specifically, the electric field gradually weakens from the top to bottom of NCNR, and direction of the electric field lines is not vertical at the surface of the NCNR. Hence, the densities of the $\mathrm{N}^{+}$ and $\mathrm{NH}_{3}{ }^{+}$ion fluxes reaching the surface of NCNR are different, and BNCONFs are formed in the different areas. The BN molecules orient along the direction of electric filed lines due to the polarization in the electric field, i.e., the growing BNCOBFs are not perpendicular to the surfaces of NCNRs. Consequently, these diversified BNCONFs on the NCNR form the pillar BNCO/NCNR hybrid network structure. 


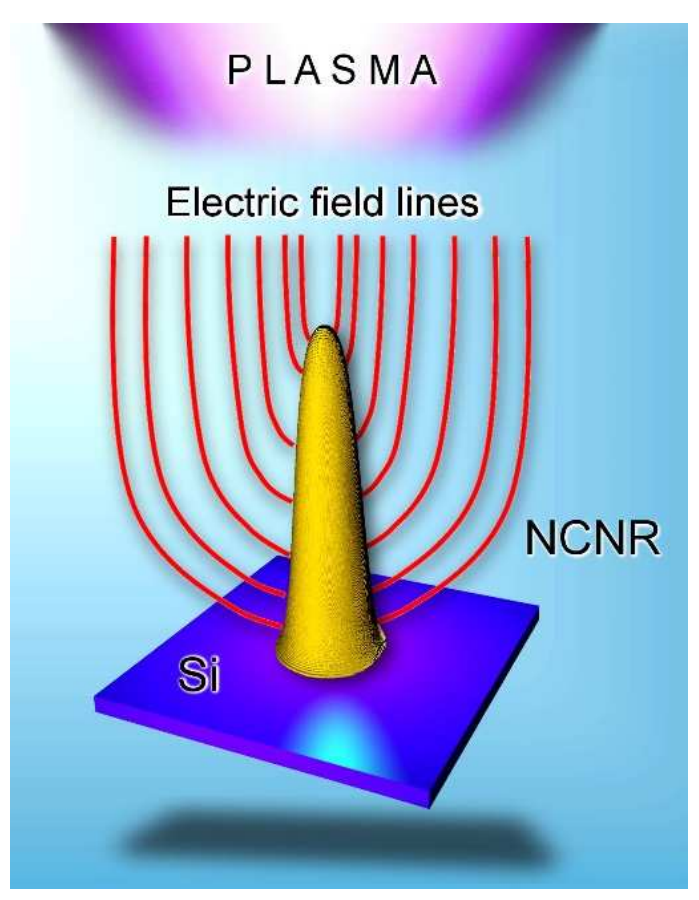

Figure 6. Schematics of the electric field near nitrogenated carbon nanorod

\subsection{PL properties of Samples}

Figure 7 is the PL spectra obtained from different measurement places on the samples A-E at the room temperature. From these graphs one can see that both the aligned BNCONFs and pillar BNCONF/NCNR hybrid networks generate the ultraviolet (UV) PL band at about $384 \mathrm{~nm}$, blue PL bands at $409-478 \mathrm{~nm}$, green PL bands at about $495-509 \mathrm{~nm}$, and red PL bands at about $751-752 \mathrm{~nm}$. The NCNRs emit very weak green PL bands at about $506-$ $508 \mathrm{~nm}$. Importantly, Fig. 7 shows that the pillar network sample D emits weaker photoluminescence than the aligned BNCONF sample A, while the pillar network sample E generates stronger photoluminescence than sample A. 


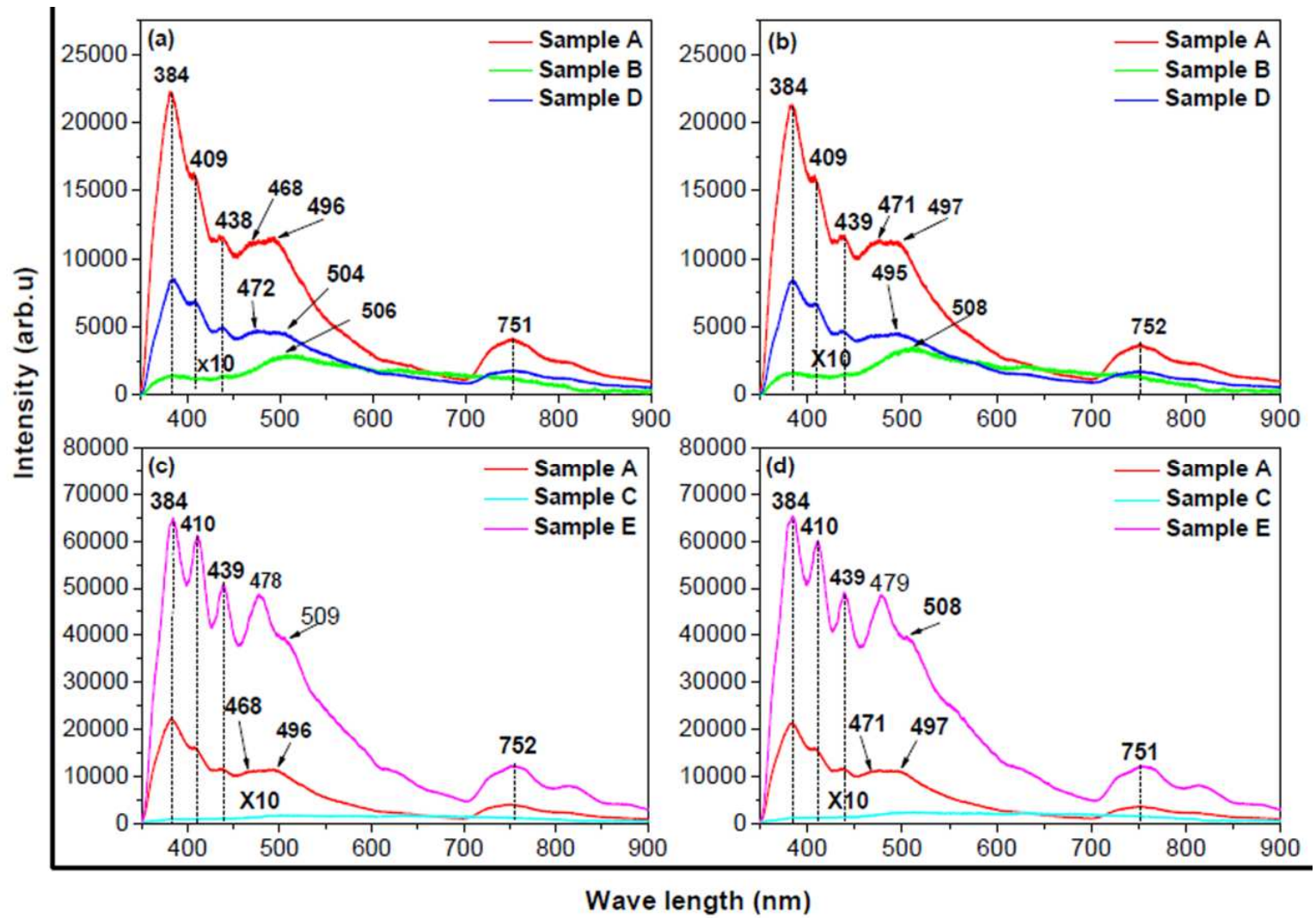

Figure 7. PL spectra obtained from different places on samples A - E. The aligned BNCONFs and pillar BNCONF/NCNR hybrid networks generate the UV band at about $384 \mathrm{~nm}$, blue PL bands at about 409-478 nm, green PL bands at about 495-509 nm and red PL bands at about 751-752 nm, while the NCNRs generate very green PL bands compared to the BNCONFs and BNCONF/NCNR hybrid networks.

\subsubsection{Generation of PL bands}

In the previous works $[13,21,36,46-49]$, the PL generation of BNCONFs and NCNRs has been studied. Due to the carbon doping of h-BN nanoflakes, carbon easily separates from BN and forms carbon clusters [12], thus the UV PL band is related to BN [13], while the blue and green PL bands are associated with the carbon and oxygen impurity levels and carbon clusters $[13,21,36,46-49]$. The generation of UV PL band at about $384 \mathrm{~nm}$ can be attributed to the transition between the nitrogen vacancy and carbon impurity levels, where the nitrogen vacancy level is related to the three boron centres [13, 48, 49]. Zhang et al. attributed the blue 
and green band generation to the change of carbon and oxygen impurity levels affectd by the impurity concentration $[13,36,48,49]$. When the impurity concentration increases, the impurity levels shift toward conduction band, thus the transition between the nitrogen vacancy and impurity levels generates the blue and green bands [13, 36, 48, 49]. However, the carbon clusters are easily formed in the BNCONFs [12]. The FTIR and XPS results indicate the presence of $\mathrm{C}-\mathrm{N}$ bonds in the BNCONF sample and pillar BNCONF/NCNR networks, i.e., it is possible that the lone pair (LP) electrons exist in the C-N bonds of carbon clusters [47], and hence, there is a level related to the LP electrons [50]. As a result, transition between the $\pi^{*}$ band and the level related to the LP electrons also leads to the generation of blue PL bands, and moreover, transition between the $\pi^{*}$ and $\pi$ bands also emit the green PL bands [47]. Since the bandgap of carbon clusters changes with their sizes [46,47], the diversified carbon clusters can emit the multi- blue and green PL. Thus, the blue and green bands at about 409-509 nm relate to carbon and oxygen impurity levels and carbon clusters, whereas the red emission bands are related to the defect level related to carbon and $s p^{3}$-hybridized $\mathrm{BN}$ bonds. In the BNCONFs, carbon atoms can form different carbon-related defect levels such as $\mathrm{C}_{\mathrm{B}}(\mathrm{B}$ atom is replaced with carbon atom), $\mathrm{C}_{\mathrm{N}}\left(\mathrm{N}\right.$ atom is replaced with carbon atom) and $\mathrm{C}_{1}$ (interstitial carbon) [36]. From the energy level diagram of the BNCO system it appears that the $\mathrm{C}_{1}$ level is below the conduction band at about $1.7 \mathrm{eV}$ [36], i.e., the transition between the conduction band and $\mathrm{C}_{1}$ level can generates the red emission. Furthermore, the curvature of the h-BN structure can induce formation of the $s p^{3}$-hybridized BN bonds, and the cathodoluminescence at about $700 \mathrm{~nm}$ related to $s p^{3}$-hybridized $\mathrm{BN}$ bonds was observed at low temperature of $20-80 \mathrm{~K}[51,52]$. Thus, the red bands at about $751-752 \mathrm{~nm}$ are associated with the transition between conduction band, carbon defect level, and the $s p^{3}$-hybridized BN bonds. 


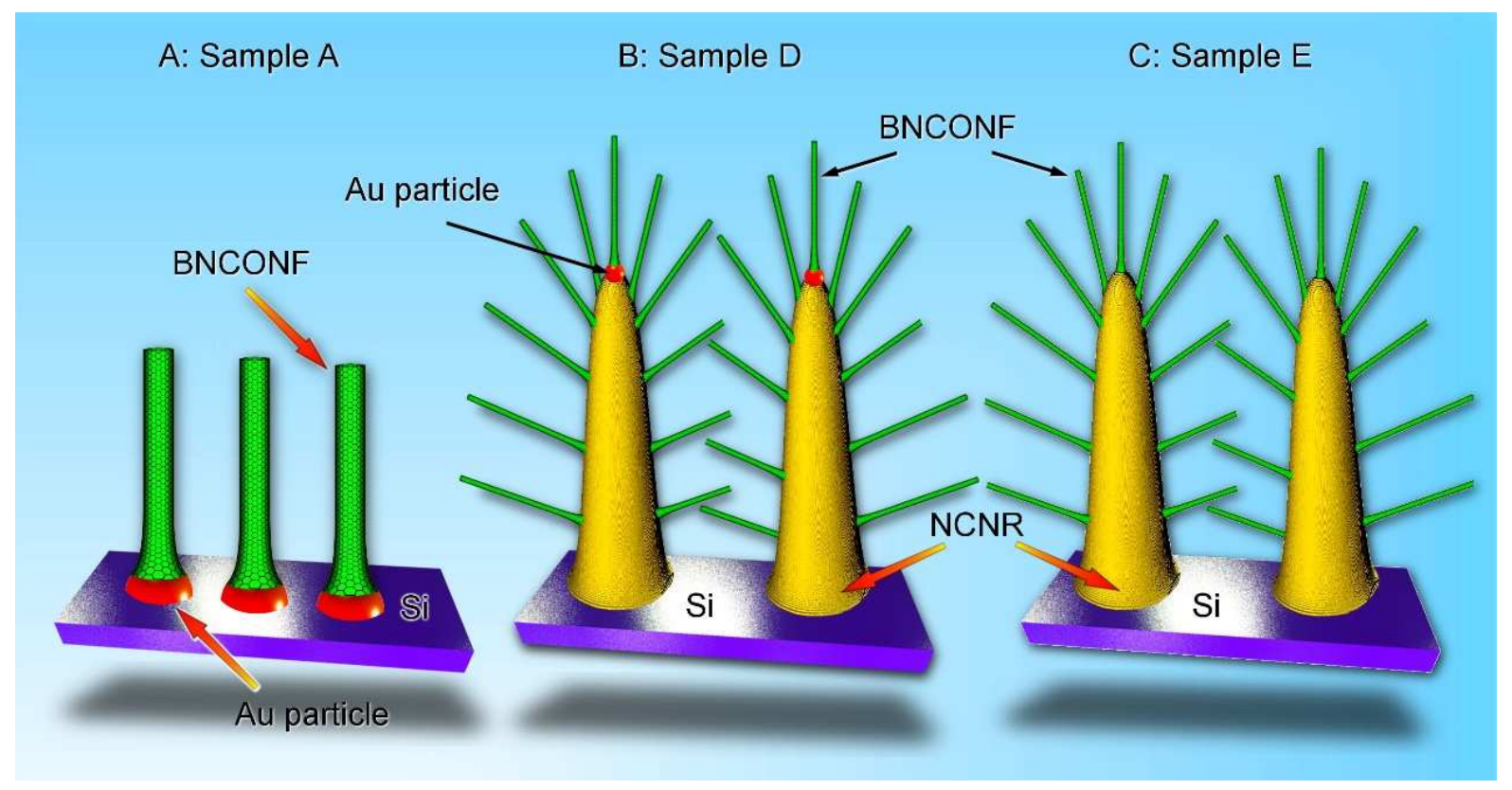

Figure 8. Schematic of the aligned BNCONF and pillar BNCONF/NCNR hybrid network structures. Sample A features the Au-BNCONF interface, sample D features both BNCONF-NCNR and BNCONF-Au interface zones, whereas BNCONF-Au interface zones are absent in sample E.

\subsubsection{Differences in PL properties between samples}

From Fig. 1(b) and (c) one can obviously see that the gold nanoparticles are located on the tops of NCNRs of sample B, while gold nanoparticles are removed from the tops of NCNRs of sample C. Simultaneously, the NCNRs in sample C are higher than in sample B. Furthermore, Fig. 1(a) shows that the BNCONFs in sample A are aligned with respect to the silicon substrate, while Fig.1 (d) and (e) indicate that the BNCONFs in samples D and E are tilted. Structures of the aligned BNCONF and pillar BNCONF/NCNR hybrid networks shown in Fig. 1(a), (d) and (e) are schematically illustrated in Figure 8.

When the laser irradiates sample A, the electrons in the valence band of BNCONFs are excited to the conduction band of BNCONFs, and this leads to the migration of electrons from the conduction band to the valence band. As a result, sample A emits the PL bands through the 
transition between conduction and valence bands. Since the BNCONFs are aligned, the excitation intensity of laser in the BNCONFs decays with the increasing of incoming depth in the BNCONFs [53], thus the effect of the BNCONF-Au/Si interface zones on the PL generation shown in Fig. 8(a) will be weak. In other words, the PL emission of sample A mainly generates from the BNCONFs.

Fig. 8 (b) and (c) related to the pillar BNCONF/NCNR hybrid networks show that there are the BNCONF-NCNR and BNCONF-Au interface zones in sample D, while BNCONF-Au interface zones are absent in sample E. Due to the same excitation conditions, these interface zones are easily irradiated by laser because the BNCONFs grown on the NCNRs are tilted. As a consequence, some electrons which are excited to the conduction band by laser move to the interface zones. Some excited electrons are scattered in the BNCONF-NCNR interface zones [54], and this lowers the recombination probability of electrons with vacancies. However, the excited electrons reaching the BNCONF-Au interface zones are transferred by gold nanoparticle due to the good conductivity of gold [55]. Furthermore, there are some dangling bonds in the BNCONF-Au interface zones due to the defects of gold nanoparticle surfaces [56], which further lowers the recombination probability of electrons with vacancies. Thus, the interface zones are responsible for the PL quenching. Due to the tilt of thin BNCONFs in the pillar BNCONF/NCNR hybrid network structures, the decay of laser in the BNCONFs is very weak, thus the reduction of PL intensity of sample D compared to sample A can be attributed to the scattering of electrons in the BNCONF-NCNR interface zones and transfer of electrons by gold nanoparticles in the BNCONF-Au interface zones. With respect to sample E we can note that the BNCONF-Au interface zones are reduced due to the removal of some gold nanoparticles from the NCNR tops, and this weakens the PL quenching. Furthermore, the 
high NCNRs of sample C relative to sample B implies that the number of BNCONFs is increased, i.e., the PL emitting volume is enhanced; these are the possible reasons why sample E emits stronger PL bands than sample A.

Samples B and C are amorphous carbon materials which belong to weak PL materials, thus their PL intensities are weaker than that of samples A, D and E shown in Fig. 7.

According to the above analyses, the PL properties of pillar BNCONF/NCNR hybrid network structures are related to the number of BNCONFs on the NCNRs and gold nanoparticles on the tops of NCNRs, and the PL properties of BNCONF can be tuned by changing the BNCONF/NCNR hybrid structure morphology, depending on the height of nanorods.

\section{Conclusion}

In summary, pillar BNCO nanoflake/nanorod hybrid networks were synthesized by the plasma-enhanced hot filament chemical vapour deposition. The nanorods were grown on the silicon substrates covered with gold films in $\mathrm{CH}_{4}-\mathrm{N}_{2}-\mathrm{H}_{2}$ plasma, followed by the direct growth of BNCONFs in $\mathrm{N}_{2}-\mathrm{H}_{2}$ plasma using $\mathrm{B}_{4} \mathrm{C}$ as the precursors of boron and carbon. The structure and composition of the synthesized BNCONFs and pillar BNCONF/NCNR hybrid networks were studied using a series of characterization instruments including FESEM, TEM, micro-Raman spectroscope, FTIR and XPS. The studies indicate that the formation of pillar BNCONF/NCNR networks originates from the nucleation and self-assembly of BN molecules on the amorphous NCNRs depending on the dangling bonds formed on the surfaces of NCNRs by ion bombardment. The PL properties of BNCONFs and pillar BNCONF/NCNR hybrid networks were studied at room temperature, and the results show that the PL properties 
can be tuned by the BNCONF/NCNR hybrid network structure and morphology due to the existence of interface zones and gold nanoparticles on the tops of NCNRs. These achievements can contribute to the fabrication of hybrid nanostructures and the development of next generation optoelectronic nanodevices and power devices [57].

\section{Acknowledgements}

This work was partially supported by CSIRO's OCE Science Leadership Scheme and the

Australian Research Council. I.L. acknowledges the support from the School of Chemistry, Physics and Mechanical Engineering, Science and Engineering Faculty, Queensland University of Technology.

\section{References}

[1] D. H. Seo, S. Yick, Z. J. Han, J. H. Fang, and K. Ostrikov, Synergistic fusion of vertical graphene nanosheets and carbon nanotubes for high-performance supercapacitor electrodes, ChemSusChem 7 (2014) 2317-2324.

[2] S. Badhulika, T. Terse-Thakoor, C. Villarreal, A. Mulchandani, Graphene hybrids: synthesis strategies and applications in sensors and sensitized solar cells, Frontiers in Chemistry, 3 (2015) 38-19 (doi: 10.3389/fchem.2015.00038).

[3] K. Roy, M. Padmanabhan, S. Goswami, T. P. Sai, G. Ramalingam, S. Raghavan, A. Ghosh, Graphene-MoS hybrid structures for multifunctional photoresponsive memory devices, Nat. Nanotechnol. 8 (2013) 826-830.

[4] S. Mao, Z. Wen, S. Ci, X. Guo, K. Ostrikov, J. Chen, Perpendicularly oriented $\mathrm{MoSe}_{2} /$ graphene nanosheets as advanced electrocatalysts for hydrogen evolution, Small 11 ( 2015) 414-419.

[5] M. K. Kavitha, S. C. Pillai, P. Gopinath, H. John, Hydrothermal synthesis of ZnO decorated reduced graphene oxide: Understanding the mechanism of photocatalysis, J. Environmental Chem. Eng. 3 (2015) 1194-1199.

[6] H. Bi, H. Cui, T. Lin, F. Huang, Graphene wrapped copper-nickel nanospheres on highly conductive graphene film for use as counter electrodes of dye-sensitized solar cells, Carbon 91 (2015) 153-160.

[7] F. Shayeganfar, R. Shahsavari, Electronic and pseudomagnetic properties of hybrid carbon/boronnitride nanomaterials via ab-initio calculations and elasticity theory, Carbon 99 (2016) 523-532.

[8] N. Jain, T. Bansal, C. A. Durcan, Y. Xu, B. Yu, Monolayer graphene/hexagonal boron nitride heterostructure, Carbon 54 (2013) 396-402.

[9] L. Ma, X. Zhou, L. Xu, X. Xu, L. Zhang, W. Chen, Ultrathin few-layered molybdenum selenide/graphene hybrid 
with superior electrochemical Li-storage performance, J. Power Sources 285 (2015) 274-280.

[10] J. Xue, J. Sanchez-Yamagishi, D. Bulmash, P. Jacquod, A. Deshpande, K. Watanabe, T. Taniguchi, P. Jarillo-Herrero, B.J. LeRoy, Scanning tunneling microscopy and spectroscopy of ultra-flat graphene on hexagonal boron nitride, Nat. Mater. 10 (2011) 282-285.

[11] M. O. Watanabe, S. Itoh, T. Sasaki, K. Mizushima, Visible-Light-Emitting Layered $\mathrm{BC}_{2} \mathrm{~N}$ Semiconductor, Phys. Rev. Lett. 77 (1996) 187-189.

[12] Q. Weng, X. Wang, X. Wang, Y. Bando, D. Golberg, Functionalized hexagonal boron nitride nanomaterials: emerging properties and applications, Chem. Soc. Rev. 45 (2016) 3989-4012.

[13] X. Zhang, L. Li, Z. Lu, J. Lin, X. Xu, Y. Ma, X. Yang, F. Meng, J. Zhao, C. Tang, Effects of carbon and oxygen impurities on luminescence properties of BCNO phosphor, J. Am. Ceram. Soc. 97 (2014) 246-250.

[14] M. Kan, Y. Li, Q. Sun, Recent advances in hybrid graphene-BN planar structures, WIREs Comput. Mol. Sci. 6 (2016) 65-82.

[15] C. R. Dean, A. F. Young, P. Cadden-Zimansky, L.Wang, H. Ren, K.Watanabe, T. Taniguchi, P. Kim3, J. Hone, K. L. Shepard, Multicomponent fractional quantum Hall effect in graphene, Nat. Phys. 7 (2011) 693-696.

[16] M. Yankowitz, J. Xue, D. Cormode, J. D. Sanchez-Yamagishi, K.Watanabe, T. Taniguchi, P. Jarillo-Herrero, P. Jacquod, B. J. LeRoy, Emergence of superlattice Dirac points in graphene on hexagonal boron nitride, Nat. Phys. 8 (2012) 382-386.

[17] M. Wang, S. K. Jang, Y. J. Song, S. Lee, CVD growth of graphene under exfoliated hexagonal boron nitride for vertical hybrid structures, Mater. Res. Bulletin 61 (2015) 226-230.

[18] F. Shayeganfar, R. Shahsavari, Oxygen- and lithium-doped hybrid boron-nitride/carbon networks for hydrogen storage, Langmuir (in press, DOI: 10.1021/acs.langmuir.6b02997)

[19] N. Sakhavand, R. Shahsavari, Synergistic behavior of tubes, junctions, and sheets imparts mechano-mutable functionality in 3D porous boron nitride nanostructures, J. Phys. Chem. C 118 (2014) $22730-22738$.

[20] B. Ozturk, A. de-Luna-Bugallo, E. Panaitescu, A. N. Chiaramonti, F. Liu, A. Vargas, X. Jiang, N. Kharche, O. Yavuzcetin, M. Alnaji, M. J. Ford, J. Lok, Y. Zhao, N. King, N. K. Dhar, M. Dubey, S. K. Nayak, S. Sridhar, S. Kar, Atomically thin layers of B-N-C-O with tunable composition, Sci. Adv. 1 (2015) e1500094-8.

[21] B. B. Wang, M. K. Zhu, K. Ostrikov, I. Levchenko, M. Keidar, R. W. Shao, K. Zheng, D. Gao, Conversion of vertically-aligned boron nitride nanowalls to photoluminescent $\mathrm{CN}$ compound nanorods: Efficient composition and morphology control via plasma technique, Carbon 109 (2016) 352-362.

[22] B. B. Wang, D. Gao, I. Levchenko, K. Ostrikov, M. Keidar, M. K. Zhu, K. Zheng, B. Gao, Self-organized graphene-like boron nitride containing nanoflakes on copper by low temperature $\mathrm{N}_{2}+\mathrm{H}_{2}$ plasma, RSC Adv. 6 (2016) 87607-87615.

[23] B. B. Wang, K. Zhu, K. Ostrikov, R. W. Shao, K. Zheng, Structure and photoluminescence properties of carbon nanotip-vertical graphene nanohybrids, J. Appl. Phys. 119 (2016) 024302-7.

[24] T. S. Ashton, A. L. Moore, Three-dimensional foam-like hexagonal boron nitride nanomaterials via atmospheric pressure chemical vapor deposition, J. Mater. Sci. 50 (2015) 6220-6226.

[25] H. Zhou, J. Zhu, Z. Liu, Z. Yan, X. Fan, J. Lin, G. Wang, Q. Yan, T. Yu, P. M. Ajayan, J. M. Tour, High thermal conductivity of suspended few-layer hexagonal boron nitride sheets, Nano Res. 7 (2014) 1232-1240. 
[26] I. Ahmad, M. Usman, S. R. Naqvi, J. Iqbal, L. Bo, Y. Long, C. F. Dee, A. Baig, Substitutional carbon doping of hexagonal multi-walled boron nitride nanotubes (h-MWBNNTs) via ion implantation, J. Nanopart. Res. 16 (2014) $2170-8$.

[27] A. W. Musumeci, R. L. Frost, and E. R. Waclawik, A spectroscopic study of the mineral paceite (calcium acetate), Spectrochimica Acta Part A 67, 649-661 (2007).

[28] E. Fuente, J. A. Menéndez, M. A. Díez, D. Suárez, M. A. Montes-Morán, Infrared spectroscopy of carbon materials: A quantum chemical study of model compounds, J. Phys. Chem. B 107 (2003) 6350-6359.

[29] H. Werheit, T. Au, R. Schmechel, IR-active phonons and structure elements of isotope-enriched boron carbide, J. Solid State Chem. 154 (1999) 79-86.

[30] Y. Zhang, H. Gao, Y. Gu, Structure studies of $\mathrm{C}_{3} \mathrm{~N}_{4}$ thin films prepared by microwave plasma chemical vapour deposition, J. Phys. D: Appl. Phys. 34 (2001) 299-302.

[31] T. Ikuno, T. Sainsbury, D. Okawa, J.M.J. Fŕechet, A. Zettl, Amine-functionalized boron nitride nanotubes, Solid State Commun. 142 (2007) 643-646.

[32] C. Tang, Y. Bando, C. Zhi, D. Golberg, Boron-oxygen luminescence centres in boron-nitrogen systems, Chem. Commun., 2007, 4599-4601.

[33] S. Pandiarajan, M. Umadevi, V. Sasirekha, R. K. Rajaram, V. Ramakrishnan, FT-IR and FT-Raman spectral studies of bis(L-proline) hydrogen nitrate and bis(L-proline) hydrogen perchlorate, J. Raman Spectrosc. 2005; 36: 950-961.

[34] I. I. Vlasov, V. G. Ralchenko, E. Goovaerts, A. V. Saveliev, M. V. Kanzyuba, Bulk and surface-enhanced Raman spectroscopy of nitrogen-doped ultrananocrystalline diamond films, Phys. Stat. Sol. (a) 203 (2006) 3028-3035.

[35] C. D. Wagner, W. M. Riggs, L. E. Davis, J. F. Moulder, G. E. Muilenberg, Handbook of X-ray Photoelectron Spectroscopy, Perkin-Elmer Corp., Physical Electronics Division, USA, 1979.

[36] X. Zhang, X. Jia, H. Liu, Z. Lu, X. Ma, F. Meng, J. Zhao, C. Tang, Spectral properties and luminescence mechanism of red emitting BCNO phosphors, RSC Adv. 5 (2015) 40864-40871.

[37] Y. V. Butenko, L. Alves, A. C. Brieva, J. Yang, S. Krishnamurthy, L. Šiller, X-ray induced decomposition of gold nitride, Chem. Phys. Lett. 430 (2006) 89-92.

[38] N. Lange, P. M. Dietrich, A. Lippitz, N. Kulak, W. E. S. Unger, New azidation methods for the functionalization of silicon nitride and application in copper-catalyzed azide-alkyne cycloaddition (CUAAC), Surf. Interface Anal. 48 (2016) 621-625.

[39] C. Huang, C. Chen, M. Zhang, L. Lin, X. Ye, S. Lin, M. Antonietti, X. Wang, Carbon-doped BN nanosheets for metal-free photoredox catalysis, Nat. Commun.6 (2015) 7698-7.

[40] Y. Yan, K. Zheng, J. Wang, M. Zheng, B. Wang, X. Quan, Catalytic growth mechanism and catalyst effects on electron field emission of nitrogenated carbon nanorods formed by plasmaenhanced hot filament chemical vapor deposition, Vacuum 101 (2014) 283-290.

[41] H. Nagai, S. Takashima, M. Hiramatsu, M. Hori, T. Goto, Behavior of atomic radicals and their effects on organic low dielectric constant film etching in high density $\mathrm{N}_{2} / \mathrm{H}_{2}$ and $\mathrm{N}_{2} / \mathrm{NH}_{3}$ plasmas, J. Appl. Phys. 91 (2002) 2615-2621.

[42] P. Liu, S.C. Mao, L.H. Wang, X.D. Hana, Z. Zhang, Direct dynamic atomic mechanisms of strain-induced 
grain rotation in nanocrystalline, textured, columnar-structured thin gold films, Scripta Mater. 64 (2011) 343-346.

[43] L. Wang, P. Liu, P. Guan, M. Yang, J. Sun, Y. Cheng, A. Hirata, Z. Zhang, E. Ma, M. Chen, X. Han, In situ atomic-scale observation of continuous and reversible lattice deformation beyond the elastic limit, Nat. Commun. 4 (2013) 2413-7.

[44] Z. Bo, S. Mao, Z.J. Han, K. Cen, J. Chen, K. Ostrikov, Emerging energy and environmental applications of vertically-oriented graphenes, Chem. Soc. Rev. 44 (2015) 2108-2121.

[45] I. Levchenko, K. Ostrikov, A. E. Rider, E. Tam, S. V. Vladimirov, S. Xu, Growth kinetics of carbon nanowall-like structures in low-temperature plasmas, Phys. Plasmas 14 (2007) 063502-8.

[46] B. B. Wang, K. Zheng, D. Gao, I. Levchenko, K. Ostrikov, M. Keidar, S. S. Zou, Plasma-chemical synthesis, structure and photoluminescence properties of hybrid graphene nanoflake-BNCO nanowall systems, J. Mater. Chem. C 4 (2016) 9788-9797.

[47] B. B. Wang, Q. J. Cheng, L. H. Wang, K. Zheng, K. Ostrikov, The effect of temperature on the mechanism of photoluminescence from plasma-nucleated, nitrogenated carbon nanotips, Carbon 50 (2012) 3561-3571.

[48] X. Zhang, S. Yan, Y. Cheng, K. Gao, Z. Lu, F. Meng, J. Lin, X. Xu, J. Zhao, C. Tang, Spectral properties of BCNO phosphor with wide range of excitation and emission, Mater. Lett. 102-103 (2013) 102-105.

[49] X. Zhang, Z. Lu, H. Liu, J. Lin, X. Xu, F. Meng, J. Zhao, C. Tang, Blue emitting BCNO phosphors with high quantum yields, J. Mater. Chem. C 3 (2015) 3311-3317.

[50] Y. Iwano, T. Kittaka, H. Tabuchi, M. Soukawa, S. Kunitsugu, K. Takarabe, K. Itoh, Study of amorphous carbon nitride films aiming at white light emitting devices. Jpn. J. Appl. Phys. 47 (2008) 7842-7844.

[51] H. Z. Zhang, M. R. Phillips, J. D. Fitz Gerald, J. Yu, Y. Chen, Patterned growth and cathodoluminescence of conical boron nitride nanorods, Appl. Phys. Lett. 88 (2006) 093117-3.

[52] Y.-C.n Zhu, Y. Bando, D.-F. Xue, T. Sekiguchi, D. Golberg, F.-F. Xu, Q.-L. Liu, New boron nitride whiskers: showing strong ultraviolet and visible light luminescence, J. Phys. Chem. B 108 (2004) 6193-6196.

[53] M. Fox, Optical Properties of Solids, Oxford University Press, 2001.

[54] J. González, F. Guinea, J. Herrero, Propagating, evanescent, and localized states in carbon nanotube-graphene junctions, Phys. Rev. B 79 (2009) 165434-10.

[55] M. K. Kavitha, S. C. Pillai, P. Gopinath, H. John, Hydrothermal synthesis of ZnO decorated reduced graphene oxide: Understanding the mechanism of photocatalysis, J. Environ. Chem. Eng. 3 (2015) 1194-1199.

[56] L. Wang, X. Han, P. Liu, Y. Yue, Z. Zhang, E. Ma, In situ observation of dislocation behavior in nanometer grains, Phys. Rev. Lett. 105 (2010) 135501-4.

[57] S. Xu, S. Y Huang, I. Levchenko, H. P. Zhou, D. Y. Wei, S. Q. Xiao, L. X. Xu, W. S. Yan, K. Ostrikov, Highly efficient silicon nanoarray solar cells by a single-step plasma-based process, Adv. Energy Mat. 1 (1011) 373-37. 